\title{
Performance Evaluation of C.I. engine with change in different engine variables and using methyl ester of Argemone Mexicana
}

\author{
Nikhil Sutar*and M.H. Attal \\ Mechanical department, Pune University, India \\ Accepted 15 June 2016, Available online 20 June 2016, Special Issue-5 (June 2016)
}

\begin{abstract}
Nowadays high prices of energy motivates industry to look for alternatives which are reliable, cost effective and eco friendly. Fatty acid methyl or ethyl esters derived from vegetable oils or animal fats is turning out to be great alternative because of its renewablity, biodegradibilty and highly oxygenated nature etc properties. The various engine parameters such as compression ratio, fuel injection pressure, load etc has profound effect on the performance and emission of compression ignition engine. There is need to optimise these parameters so that efficiency of engine is increased and emissions from the engine is lowered. So in this paper, attempt has been made to look for effect of compression ratio, fuel injection pressure and load. Some blends of methyl ester of Argemone Mexicana oil is used to check and evaluate the performance of compression injection diesel engine.
\end{abstract}

Keywords: Methyl ester of vegetable oil, compression ignition engine, compression ratio

\section{Introduction}

Rapid depletion of nonrenewable energy resources such as gasoline, natural gas etc and hazardous effect of pollutants coming from compression ignition engine exhaust on the enviornment are the two critical problems currently faced by automobile sector. Also the prices of these energy resources are swelling day by day. Thus the money driven industry is looking for an alternative which will substitute the diesel. Methyl ester or ethyl ester derived from any vegetable oil or animal fat is found to be best alternative for the diesel in compression ignition engine with or without engine modification.

Methyl ester or ethyl ester which is transesterified renewable fuel derived from vegetable oil is commonly termed as biodiesel has shown properties similar to diesel. The high content of oxygen in fuel, renewablity, biodegradibility, non flammability, higher cetane number these are some of the properties of biodiesel which makes it one of the possible alternative to diesel. The parameters such as compression ratio, fuel injection pressure, number of holes of injecting nozzle, diameter of injector holes, injection timing etc has varying effect on performance and emission of compression ignition engine. Higher compression ratio and higher injection pressure has positive effect on performance and emission of compression ignition engine. The effect of compression ratio on an engine fuelled with waste oil produced biodiesel/diesel fuel

*Corresponding author: Nikhil Sutar was studied. Wasted cooking oil from restaurants was used to produce neat (pure) biodiesel through transesterification and then used to prepare biodiesel/diesel blend. They also studied the emission and performance characteristics of a diesel engine by changing compression ratio from 14 to 16 to 18 with the help of variable compression engine. Ultimately they concluded that increasing the compression ratio had more benefits with biodiesel than that with pure diesel. Also They found that the brake thermal efficiency of diesel engines tested was reduced when substituting diesel by biodiesel in its blended form. The change of compression ratio from 14 to 18 resulted in $18.39 \%, 27.48 \%, 18.5 \%$, and $19.82 \%$ increase in brake thermal efficiency in case of B10, B20, B30, and B50 respectively. (Mohammed EL_Kassaby and Medhat A. Nemit_allah, 2013)

(G.R.K. Sastry,et al,2015) studied the effect of injection pressure, isobutanol and ethanol addition on performance of diesel-biodisel fuelled D.I. diesel engine. Higher fuel injection pressure is effective in improving the performance and reducing emissions. They studied the performance and emissions characteristics at different injection pressures viz. 200, 225,250 and 275 bars. They found that nozzle opening injection pressure can be increased upto 250 bar leading to increased brake thermal efficiency and fuel economy of the engine. Finally they found that, cylinder pressure increases with increase in injection pressure, in case of blended fuels. CO emissions and smoke density are found to decrease with increase in injection pressure. They also concluded that NOx emissions 
were decreased marginally by using blended fuels with isobutanol and ethanol as additives and they are found to increase with injection pressure.

(Mohamed F. Al_ Dawody and S.K.Bhatti,2014) experimentally and computationally investigated for combustion, performance and emission parameters of a diesel engine fuelled with Soyabean biodiesel-diesel blends. The study was carried on a single cylinder, direct injection diesel engine operated on different blends of a soyabean methyl ester (SME) with diesel fuel. The emissions like $\mathrm{CO}, \mathrm{CO}_{2}, \mathrm{HC}$ were significantly reduced with slight increase in NOx emissions. From their observation, they concluded that The blends of SME are found to give nearly same brake thermal efficiency as compared to diesel fuel. The BSFCs for SME and its blends were higher than for diesel fuel. The increase in the BSFC was $14.65 \%$ for neat SME. They found significant reductions in the UHC, CO and smoke opacity compared with diesel fuel. The measured NOx emissions by them are higher than that of diesel fuel for all blends of SME.

(S. Jaichandar, and K. Annamalai, 2011) under The Status of Biodiesel as an Alternative Fuel for Diesel Engine - An Overview has given an overview of biodiesel as an alternative fuel. The effect of use of biodiesel fuel on engine power, fuel consumption and thermal efficiency are collected by the author and analyzed with that of conventional diesel fuel. Also, the engine emissions from biodiesel and diesel fuels are compared in the literature, paying special attention to the most significant emissions such as nitric oxides and particulate matter. Finally they concluded that biodiesel is said to be carbon neutral as more carbon dioxide is absorbed by the biodiesel yielding plants than what is added to the atmosphere when [burnt] used as fuel.

(Jinlin xue, et al,2011) under effect of biodiesel on engine performance and emissions has done lot of research. They studied various papers and found various types of biodiesel used upto now for performance and emission analysis of diesel engine. The biodiesels include soyabean, karanja etc. Under engine performance. They studied power performance, economy performance and durability study. Under emissions analysis they studied effect on PM, NOx, CO, $\mathrm{HC}$ and other non regulated emissions. Finally they found that all emissions except NOx were decreased if biodiesel is used instead of diesel.

(A. Sanjid,et al, 2014) under experimental investigation of mustard biodiesel blend properties, performance, exhaust emission and noise in an unmodified diesel engine studied the physiochemical properties of mustard biodiesel obtained from waste mustard oil. They arrived at conclusion that MB10 and MB20 can be used in diesel engines without modification. Also Engine emission and noise test showed 9-12\% higher NO, 24-42\% lower HC, 19-40\% lower $\mathrm{CO}$ and $2-7 \%$ lower noise emission for $\mathrm{MB}$ blends compared to B0. Besides, comparable engine performance and emission characteristics were found for MB10 and MB20 compared to PB10 and PB20 respectively.

(C.S. Cheung, et al,2015) under the effect of waste cooking oil biodiesel on the emissions of diesel engine studied the effect of different mixed concentrations of biodiesel and diesel fuel, including pure diesel fuel, B10(diesel containing 10\% vol of biodiesel), B20, B30 and pure biodiesel on 4 cylinder natural aspirated direct injection diesel engine. They conducted experiments with five engine loads, corresponding to brake mean effective pressure of $0.165,0.33,0.496$, $0.661,0.753 \mathrm{MPa}$ at a constant speed of $1800 \mathrm{rpm}$. Finally they found that biodiesel leads to reduction of $\mathrm{HC}, \mathrm{CO}$ and particulate mass concentrations but an increase in NOx.

\section{Experimental setup}

The test rig used for the experiment is single cylinder, four stroke, VCR (variable compression ratio), diesel engine connected to eddy current dynamometer for loading. The compression ratio can be changed without stopping the engine and without altering the combustion chamber geometry by specially designed tilting cylinder block arrangment. Setup is provided with necessary instruments for combustion pressure and crank angle measurements. These signals are interfaced to computers through engine indicator for $\mathrm{P \theta}-\mathrm{PV}$ diagrams. Provision is also made for interfacing airflow, fuel flow, temperatures and load measurement. The has stand alone panel box consisting of air box, two fuel tanks for duel fuel test manometer, fuel measuring unit, transmitters for air and fuel measurements, process indicator and engine indicator. Rotameters are provided for cooling water and calorimeter water flow measurement.

The setup enables study of vcr engine performance for brake power, indicated power ,frictional power, BMEP, IMEP, brake thermal efficiency, specific fuel consumption, indicated thermal efficiency, volumetric efficiency, mechanical efficiency, a/f ratio and heat balance. Labview based engine performance analysis software package Engine softLV is provided for online performance evaluation. A computerized diesel injection pressure measurement is optionally provided.

Table1 Technical specification of the test engine

\begin{tabular}{|c|c|}
\hline Engine characteristics & Specification \\
\hline Make/Model & Kirloskar Oil Engine/TV1 \\
\hline Type & $\begin{array}{c}\text { Four stroke, water cooled, } \\
\text { Diesel }\end{array}$ \\
\hline No. of Cylinder & one \\
\hline Bore/Stroke & $87.5 / 110 \mathrm{~mm}$ \\
\hline Cubic Capacity & 0.661 Liters \\
\hline Compression ratio 3 port & 17.5 \\
\hline Power & 3.5 kw at 1500 rpm \\
\hline Sump capacity & 2.70 liter \\
\hline
\end{tabular}




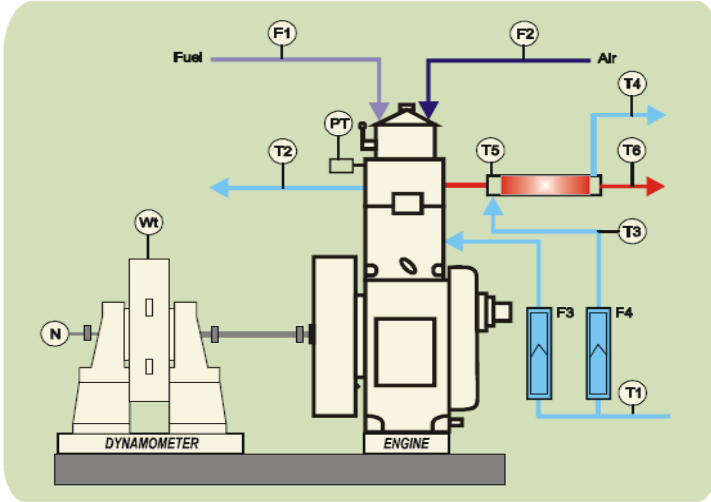

Fig.1 Schematic diagram of experimental setup

\section{Experimental methodology}

The methodology followed under this project will be as follows

\subsection{Biodisel preparation}

Biodisel is described as fatty acid methyl or ethyl esters from vegetable oils or animal fats. Vegetable oils are chemically complex esters of fatty acids. These are the fats naturally present in oil seeds, and known as triglycerides of fatty acids. The molecular weight of these tri-glycerides would be of order of $800 \mathrm{~kg} / \mathrm{m} 3$ or more. Because of their high molecular weights these fats have high viscosity causing major problems in their use as fuels in CI engines. These molecules have to be split into simpler molecules so that they have viscosity and other properties comparable to standard diesel oils. Modifying the vegetable oils (to make them lighter) can be achieved in many ways, including; Pyrolysis, Micro emulsification, Dilution and Transesterification. Among these, transesterification is the most commonly used commercial process to produce clean and environmentally friendly light vegetable oil fuel i.e. biodiesel. So choosing of proper vegetable oil, converting them into biodiesel and evaluation of their properties will be done in this phase. The biodiesel which has properties that are closer to the diesel will be the priority. Argemone mexicana biodiesel is the best suited one.

\subsection{Engine performance parameters}

Under this phase, calculation of various engine performance parameters like brake specific fuel consumption, brake thermal efficiency, brake power, torque etc will be done. The effect of biodiesel on these parameters will be analysed and compared with diesel as a engine. Also the compression ratio will be changed using tilting cylinder block arrangement and engine performance parameters will be calculated using diesel as a fuel. The same procedure will be followed with different compression ratio but using biodiesel blends as a fuel. The results will be compared of biodiesel with that of diesel. The evaluation of various engine performance parameters will be done using different fuel injection pressure with diesel as a fuel. Same procedure will be followed using biodiesel as a fuel.

Table 2 Test matrix

\begin{tabular}{|c|c|c|c|c|c|c|}
\hline \multirow{2}{*}{$\begin{array}{c}\text { Load } \\
(\mathrm{kg})\end{array}$} & \multicolumn{3}{|c|}{ Diesel } & \multicolumn{3}{c|}{ Biodiesel } \\
\cline { 2 - 7 } & \multicolumn{3}{|c|}{ CR(16,17,18) } & \multicolumn{3}{c|}{ CR(16,17,18) } \\
\cline { 2 - 7 } & \multicolumn{1}{|c|}{ njection Pressure } & \multicolumn{3}{c|}{ Injection Pressure } \\
\hline 3 & $\mathrm{x}$ & $\mathrm{x}$ & $\mathrm{x}$ & $\mathrm{x}$ & $\mathrm{x}$ & $\mathrm{X}$ \\
\hline 6 & $\mathrm{x}$ & $\mathrm{x}$ & $\mathrm{x}$ & $\mathrm{x}$ & $\mathrm{x}$ & $\mathrm{x}$ \\
\hline 9 & $\mathrm{x}$ & $\mathrm{x}$ & $\mathrm{x}$ & $\mathrm{x}$ & $\mathrm{x}$ & $\mathrm{X}$ \\
\hline 12 & $\mathrm{x}$ & $\mathrm{x}$ & $\mathrm{x}$ & $\mathrm{x}$ & $\mathrm{x}$ & $\mathrm{x}$ \\
\hline 15 & $\mathrm{x}$ & $\mathrm{x}$ & $\mathrm{x}$ & $\mathrm{x}$ & $\mathrm{x}$ & $\mathrm{X}$ \\
\hline 18 & $\mathrm{x}$ & $\mathrm{x}$ & $\mathrm{x}$ & $\mathrm{x}$ & $\mathrm{x}$ & $\mathrm{X}$ \\
\hline
\end{tabular}

The results of biodiesel using different fuel injection pressure will be compared to that of diesel.

\subsection{Exhuast emission analysis}

Under this phase, analysis of various exhaust gases will be done using exhaust gas analyser. This includes taking measurement of carbon monoxide, oxides of nitrogen, particulate matter and unburned hydrocarbons. First, with diesel as fuel the analysis of exhaust gases was done using exhaust gas analyser. In the same experiment the fuel injection pressure is changed from 200 to 220 bar in the range 200, 210, 220 bar. By keeping injection pressure constant, the compression ratio is changed from 16 to 18 in the range $16,17,18$. For each compression ratio the load is varied from 0 to $18 \mathrm{~kg}$ in the range $0,3,6,9,12,15$ and finally $18 \mathrm{~kg}$. Then using biodiesel as a fuel the measurement of carbon mononoxide, oxides of nitrogen, particulate matter, unburned hydrocarbons will be taken by following same procedure as using diesel. The effect of biodiesel on various parameters will be compared with that of diesel.

\section{Results and Discussion}

The readings are taken for diesel only at 200,210,220 bar and at various compression ratio of $16,17,18$ and at various loads i.e. 0,3,6,9,12,15,18kg. Following are some of the graphs of the result. It shows brake thermal efficiency in one graph and brake specific fuel consumption in another graph. The emission analysis is also put in tabular form. The following performance graph is for 200 bar injection pressure and compression ratio of 16,17 and 18 . The load versus brake thermal efficiency and load vs BSFC is indicated in the graph for 3 compression ratio. The graph of pressure rise in cylinder versus crank angle is also put in subsequent section. 


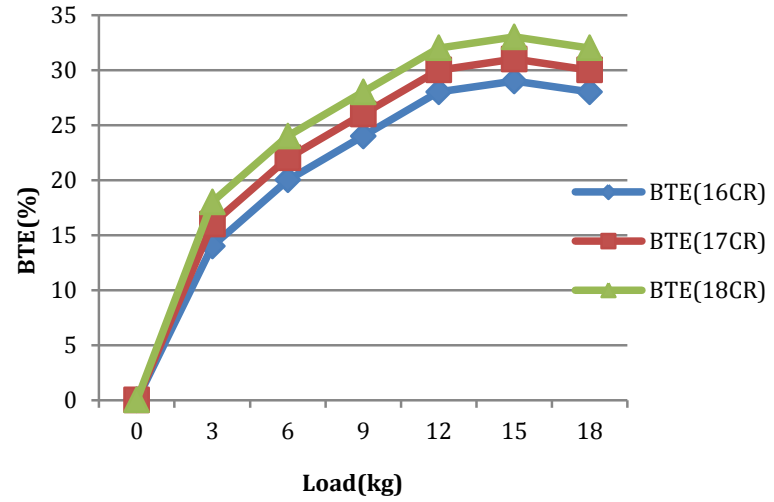

Fig.2 Load (kg) vs BTE(\%)

Fig 2 shows variation of brake thermal efficiency versus load for compression ratio of 16,17 and 18 respectively. From the figure it can be seen that as compression ratio and load increases, the brake thermal efficiency increases. The improvement in brake thermal efficiency at higher compression ratio can be attributed to reduced igition delay, better combustion and better intermixing of fuel.

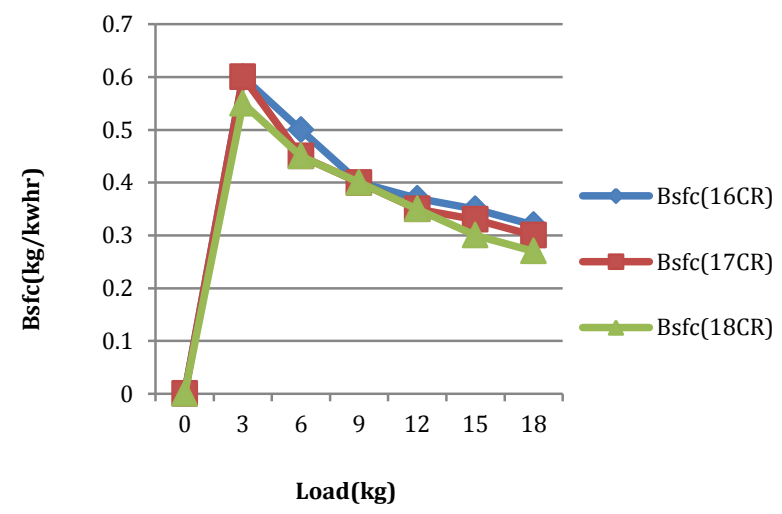

Fig.3 Load(kg) vs BSFC (kg/kwhr)

Figure 3 shows variation of brake specific fuel consumption versus load and with varying compression ratio from 16 to 18 . It is concluded that, as the compression ratio of the engine is increased, BSFC decreases (improves). Out of the 3 compression ratios, CR-18 gives lowest BSFC. This is because at higher compression ratio, brake power increases. Also, from the graph it can be concluded that as load increases brake specific fuel consumption decreases.

Figure 4 and 5 shows variation of cylinder pressure versus crank angle at compression ratio 16 and 18 respectively. As seen from the graph the peak cylinder pressure increased as compression ratio increased from 16 to 18. On the average, the percentage improvement in peak cylinder pressure is $7.40 \%$ when compression ratio is increased from 16 to 18.

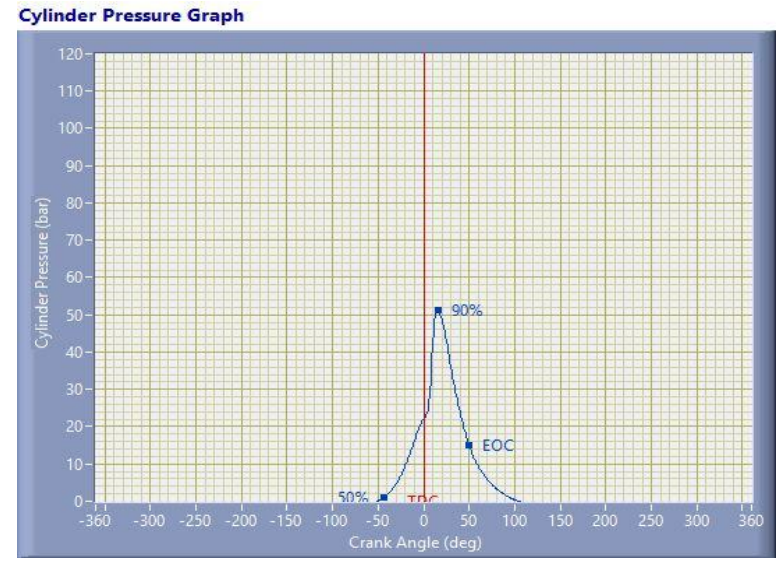

Fig.4 cylinder pressure vs crank angle at 16 Compression ratio.

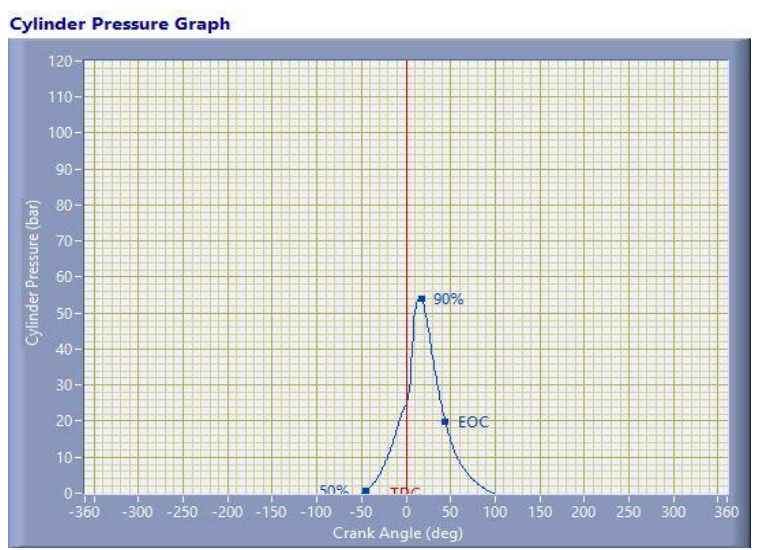

Fig.5 cylinder pressure vs crank angle at 18 compression ratio

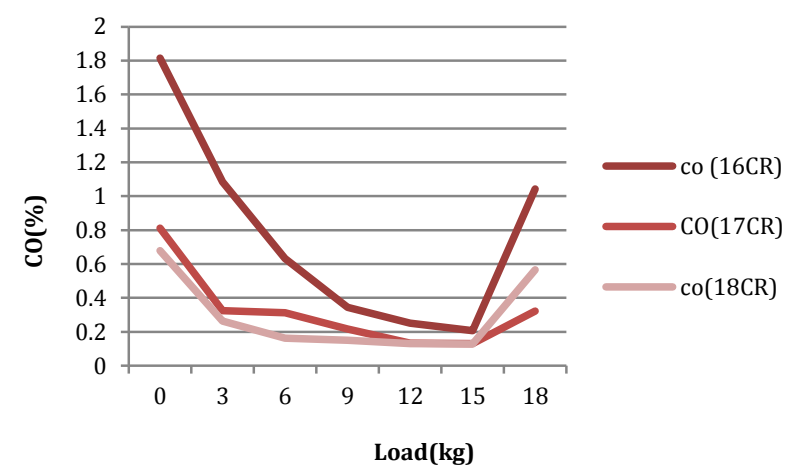

Fig.4 Load (kg) vs CO(\% vol)

The graph of emission gases also plotted. On X-axis the load is varying from 0 to18 and on $\mathrm{y}$ axis the percentage of emission gases plotted. The $\mathrm{CO}$ and $\mathrm{CO} 2$ are in percentage of volume and NOx and HC are in $\mathrm{ppm}$. From fig 4 which is a load versus $\mathrm{CO}$ graph can be seen as load increases the percentage of co decreases upto $15 \mathrm{~kg}$ of load and then at $18 \mathrm{~kg}$ load it shows increasing trend. Also, the percentage of co decreases when the compression ratio increases from 16 to18. This is due to the fact at higher load and at higher compression ratio the temperature inside cylinder becomes more and it leads to better combustion. 


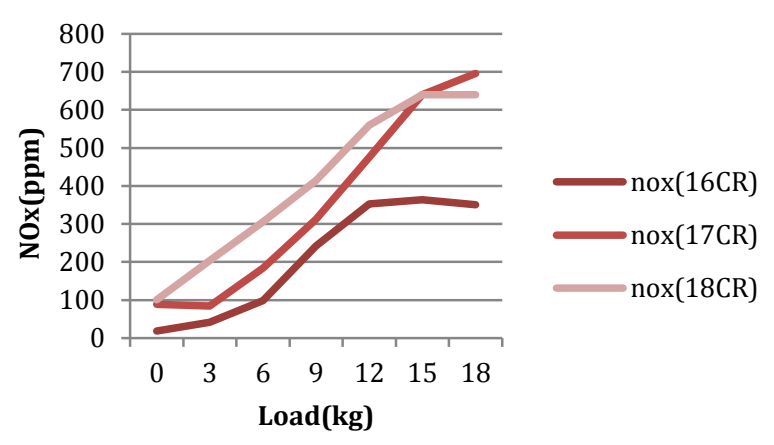

Fig.5 Load (kg) vs NOx (ppm)

But the case is not same for NOx. As seen from the fig 5 the ppm of NOx increase as load increases from 0 to 18 and with increase in compression ratio the percentage of NOx also increases due to higher combustion temperature at higher compression ratios.

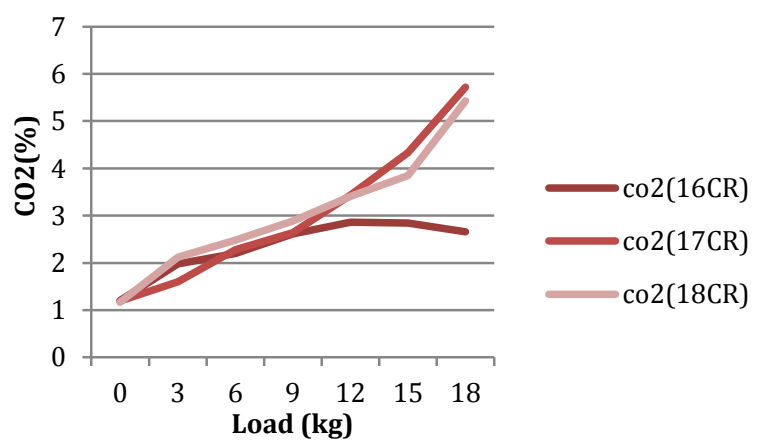

Fig.6 Load (kg) vs CO2 (\% vol)

The percentage of $\mathrm{CO} 2$ also increases with an increase in compression ratio and at higher loads as can be seen from figure 6 . The higher percentage of $\mathrm{CO} 2$ at higher compression ratios indicate better combustion due to higher combustion temperature and reduced ignition delay.

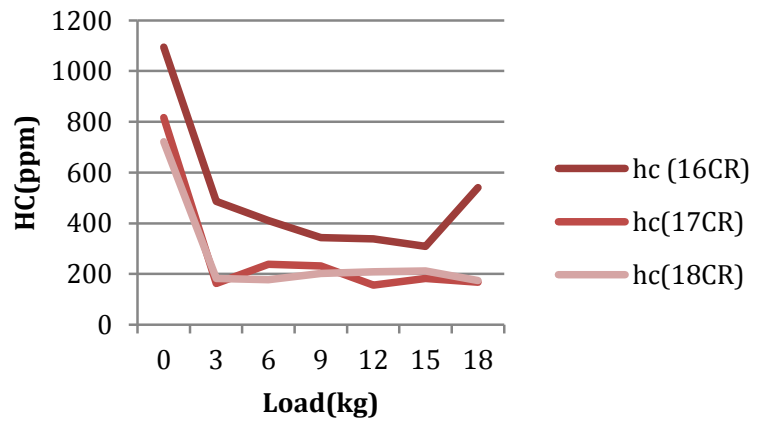

Fig .7 Load (kg) vs HC (ppm)

The better combustion leads to lower emission of hydrocarbons. From the figure 7 it can be concluded that at higher loads and at higher compression ratios there is lower emission of hydrocarbons. At higher load and higher compression ratios the air temperature inside cylinder is higher which leads to better combustion.
Fig 8 describes the variation of smoke opacity with respect to load and compression ratio. As seen from the graph the opacity increases as load increases but it shows decreasing trend when compression ratio increased from 16 to 18 . This is due to the fact that higher compression ratio leads to better combustion in the engine due to increased air temperature inside the cylinder.

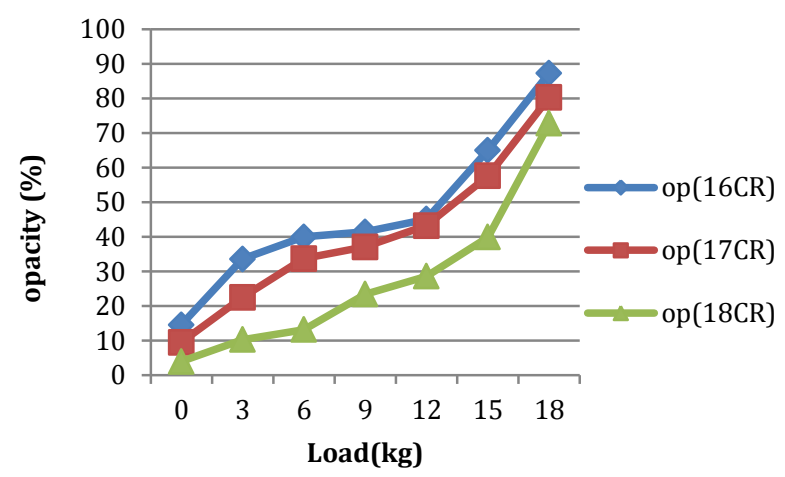

Fig .8 Load (kg) vs smoke opacity

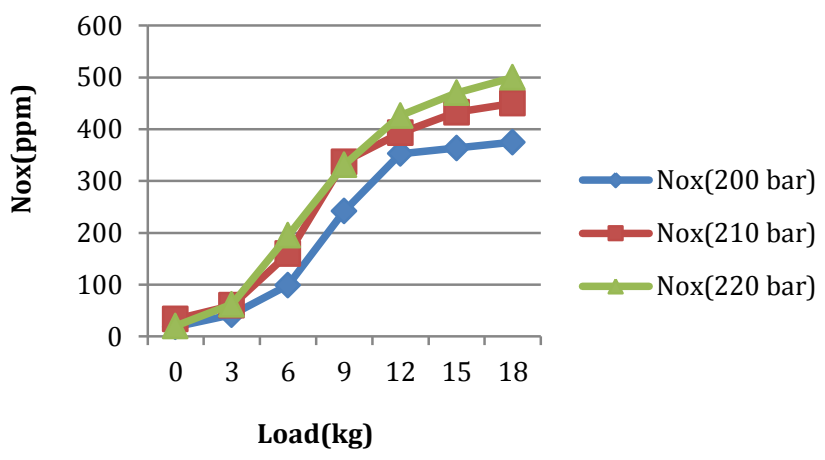

Fig.9 Load vs NOx at 16 compression ratio

Figure 9 shows the variation of NOx emission with respect to variation in load and variation in injection pressure at constant compression ratio of 16 . As seen from the graph the emission of NOx increases with increase in fuel injection pressure. This is so because at higher injection pressure there is increase in combustion temperature which is favorable condition for formation of NOx.

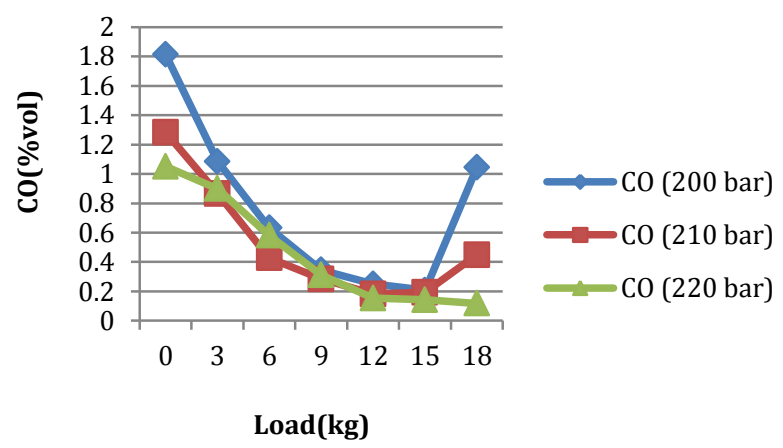

Fig.10 Load vs CO (\%vol) at 16 compression ratio 
Figure 10 shows variation of load versus percentage of $\mathrm{CO}$ at 16 compression ratio with various injection pressure such as $200,210,220$ bar. As seen from the graph the percent volume of CO decrease with increase in injection pressure because at higher injection pressure proper atomization of fuel and proper intermixing of fuel takes place which result in proper combustion and $\mathrm{CO}$ emission reduces.

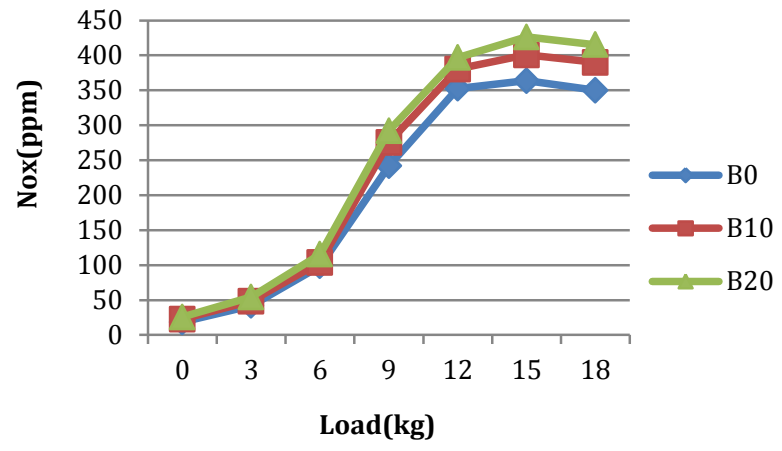

Fig.11 Load vs NOx at 16 compression ratio and 200 bar pressure

Figure 11 shows the effect of use of different blends of argemone Mexicana biodiesel in the C.I. engine with respect to load and NOx emission. As seen from the graph BO indicated pure diesel, B10 indicates $10 \%$ biodiesel and $90 \%$ pure diesel and B20 indicates $20 \%$ biodiesel and $80 \%$ diesel. As there is increase in percentage of biodiesel into the diesel the percentage of NOx increases. This is so because biodiesel is oxygenated in nature which helps in complete combustion which leads to higher temperature and formation of NOx.

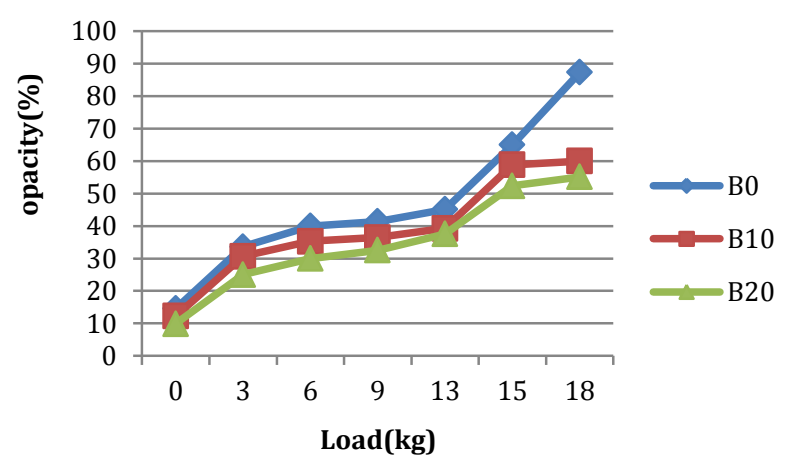

Fig.12 Load vs smoke opacity at 16 compression ratio and 220 bar pressure

Figure 12shows variation of load versus smoke opacity when different blends of argemone Mexicana biodiesel having percentage B0, B10, B20 is used. As seen from the graph the smoke opacity reduces as there is increase in biodiesel percentage in the diesel. This happens because biodiesel is oxygenated in nature which leads to complete combustion and less smoke emission.

\section{Conclusion}

The following conclusions can be drawn from this experiment. On an average the brake thermal efficiency increased by $13.33 \%$ as compression ratio increased from 16 to 18 where as BSFC reduced by around $14.2 \%$. Thus higher compression ratio gives better engine performance. On an average the $\mathrm{CO} 2$ emission increased by $25.73 \%$, NOx emission increased by $42.72 \%$, the HC emission decreased by $50.94 \%$ and CO emission decreased by $45 \%$ as compression ratio increased from 16 to18. The smoke opacity reduced by $24.58 \%$ averagely. Thus higher compression ratio gives lower $\mathrm{HC}, \mathrm{CO}$ and smoke emission but higher NOx and $\mathrm{CO} 2$ emission. So proper balance has to be maintained between these two. On an average the nox emission increased by 16.73 and $\mathrm{CO}$ emission reduced by $33.67 \%$ when injection pressure increased from 200 bar to 220 bar. So higher injection pressure is beneficial for engine performance. It is also found out that use of argemone Mexicana blends have positive effect on the engine. The NOx emission is increased by $21.83 \%$ and smoke opacity decreased by $34.56 \%$ when the diesel is replaced by B20 (20\% biodiesel and $80 \%$ diesel)blend of argemone Mexicana biodiesel.

\section{References}

Jo-Han Ng, Jing Huey Khor, Kang Yao Wong, Srithar Rajoo, Cheng Tung Chong,(2015), Statistical Analysis of Engine System-Level Factors for Palm Biodiesel Fuelled Diesel Engine Responses, The 7th International Conference on Applied Energy - ICAE, pp.99-104

Mohammed EL_Kassaby, Medhat A. Nemit_allah, (2013),Studying the effect of compression ratio on an engine fuelled with waste oil produced biodiesel/diesel fuel, Alexandria University, Alexandria Engineering Journal, vol52, pp.1-11

Mohd Hafizil Mat Yasin, Rizalman Mamat, Ahmad Fitri Yusop, Perowansa Paruka, Talal Yusaf and Gholamhassan Najafi, (2015) Effects of Exhaust Gas Recirculation (EGR) on a Diesel Engine fuelled with Palm-Biodiesel, The $7^{\text {th }}$ International Conference on applied energy, pp.30 - 36

G.R.K Sastry, Madhujit Deb, Jibitesh Kumar Panda, (2015),Effect of Fuel Injection Pressure, Isobutanol and Ethanol Addition on Performance of Diesel-Biodiesel Fuelled D.I. Diesel Engine, The 12th International Conference on Combustion \& Energy Utilisation 12ICCEU,pp.81 - 84

Mohamed F. Al Dawodya, S.K. Bhatti, (2014), Experimental and Computational Investigations for Combustion, Performance and Emission Parameters of a Diesel Engine Fueled with Soybean Biodiesel-Diesel Blends, 2013 Alternative Energy in Developing Countries and Emerging Economies , pp.421 - 430

S. Jaichandar1, and K. Annamalai2, (2011), The Status of Biodiesel as an Alternative Fuel for Diesel Engine -An Overview, Journal of Sustainable Energy \& Environment 2 ,pp.71-75

M. Mofijur, M.G. Rasul, J. Hyde, (2015), Recent Developments on Internal Combustion Engine Performance and Emissions Fuelled With Biodiesel-Diesel-Ethanol Blends, 6th BSME International Conference on Thermal Engineering (ICTE 2014) 105, pp.658 - 664

Jinlin xue, Tony E. Grift, Alan C. Hansen,(2011), Effect of biodiesel on engine performance and emissions, renewable and sustainable energy reviews, pp.1098-1116

Mr. Manish Attal, Mr. Chirag Dave, Dr. A M. Mahalle, (2014), Experimental Investigation on Performance of a Diesel Engine using Garcinia Indica (Kokam) and Rice Bran Oil based Biodiesels as Fuels, IOSR Journal of Mechanical and Civil Engineering (IOSRJMCE), pp.01-07

M H Attal, A M Mahalle , (2015), The Emissions Analysis of Diesel Engine Using GarciniaIndica and Rice Bran Oil Based Methyl Esters as Fuels with an ANN Approach, International Journal of Innovative and Emerging Research in Engineering, 